\title{
Autopoiesis in Creativity and Art
}

\author{
J. Mark Bishop \\ TCIDA, Goldsmiths \\ University of London, London, UK \\ m.bishop@gold.ac.uk \\ +44 (0) 2078962607
}

\author{
Mohammad Majid Al-Rifaie \\ Dept. Computing, Goldsmiths \\ University of London, London, UK \\ m.majid@gold.ac.uk
}

\begin{abstract}
The term autopoiesis, (meaning 'self') and 'poiesis' (meaning 'creation, production') defines a system capable of reproducing and maintaining itself. The term was introduced by the theoretical biologists, Humberto Maturana and Francisco Varela, in 1972 to define the self-maintaining chemistry of living cells. The term has subsequently also been applied to the fields of systems theory and sociology. In this paper we apply this model to characterise creativity in art practise.
\end{abstract}

\section{Author Keywords}

Creativity; Art; Autopoiesis; Embodied Cognition

\section{ACM Classification Keywords}

I.2.0. Artificial Inteligence: Philosophical Foundations

\section{INTRODUCTION}

There are many ways to think about systems that create products we socially conceive of as art. This paper is inspired by Alfred North Whitehead's process view of organisation ${ }^{1}$ [23], viewed though the transformational conceptual-lens of autopoietic theory (Maturana and Varela [15]); according to which we view a creative system as a clearly delineated and identifiable network of continuously operational component producing processes and concomitant elements, bounded as an autonomous entity within its own artistic environment.

So construed, the autopoietic artist can never be fully satisfied with her work, but continually re-engages a complex process

\footnotetext{
${ }^{1}$ For Whitehead, all real objects may be better understood as a constructed series of events and processes. It is this core idea that Whitehead explains the seminal 'Process and Reality' [23], concluding that it is process, rather than substance, that should be taken as the most fundamental metaphysical constituent of the world, "That 'all things flow' is the first vague generalization which the unsystematized, barely analysed, intuition of men has produced. Without doubt, if we are to go back to that ultimate, integral experience, unwarped by the sophistications of theory, that experience whose elucidation is the final aim of philosophy, the flux of things is one ultimate generalization around which we must weave our philosophical system", (ibid. pp. 317).
}

of 'attention' (on her current artistic context) and 'reconstitution' (of her current artistic structures), as she creatively reflects and enacts her environment.

The cycle begins as her creative processes are drawn to, and collectively attend, meaningful distinction(s) within the artistic environment; from which she selects one suitable element, an interesting 'artistic gesture' to reinterpret ${ }^{2}$. Once all the elements of the artistic context have been processed, the creative cycle is complete; the old artistic context can be discarded, and a new creative cycle begin.

In this manner the autopoietic artist continuously reflects back on the world she has just brought forth, in order to generate new re-interpretations. While these creative processes continue to produce interesting and meaningful outputs, her autopoietic unity will continue intact; conversely, if her output becomes gradually less meaningful and interesting, her creative unity will begin to dissolve and ultimately die; and the artist return to reflect upon the tabula-rasa again ${ }^{3}$.

\section{ON AUTOPOIESIS AND ALLOPOIESIS}

\section{Autopoiesis or self-creation}

Maturana and Varela's original definition of autopoiesis is found in [15]:

"An autopoietic machine is a machine organized (defined as a unity) as a network of processes of production (transformation and destruction) of components which: (i) through their interactions and transformations continuously regenerate and realize the network of processes (relations) that produced them; and (ii) constitute it (the machine) as a concrete unity in space in which they (the components) exist by specifying the topological domain of its realization as such a network", (p. 78).

Thus, the boundary of an autopoietic system is determined circularly by the production of its constituent elements; in

\footnotetext{
${ }^{2}$ By modulating the distinctions she is drawn to attend, as she creatively interacts with and explores her environment, the autopoietic artist can adapt what she construes as 'artistically meaningful' in her own historical dialogue.

3 .. in much the same way as Koskinen identifies that all business organisations eventually wither, dissolve away and ultimately die ".. decisions have to be imagined as events. In the very moment of their coming into being, they already fade away. Therefore, only little can be changed in business organizations. As decisions disappear with their appearance, they cannot be altered, but only give cause for the production of new decisions, which are subject to the same mechanism. And this is the reason why business organizations step by step wither and die", (K.U. Koskinen, 'Why do Business Organizations die? Social Autopoietic Perspective').
} 
this way the organisation of, say, a cell is both 'circular' and autopoietic because the components that specify the cell are the same components that the organisation of the cell secures and maintains. It is this circularity that maintains the cell as a living entity. It is in this sense that an autopoietic system can be considered as a special type of homeostatic system, where the variable to be maintained and controlled is the organisation and behaviour of the system. For Francisco Varela, autopoiesis is both necessary and sufficient to characterise the organisation of living, autonomous systems.

In addition to maintaining the conditions for its own continued existence, an autopoietic system may, in addition, generate allopoietic system(s) as output(s).

\section{Allopoiesis}

In contrast to autopoiesis, the operation of an allopoietic system is given in terms of the concatenation of processes. Such processes are not the processes that specify the components of the system itself, as a unity; instead the components are produced by other processes that are independent of the organisation of the system. Because the components that make up an allopoietic system's existence are contingent upon other systems, an allopoietic system is never 'fully autonomous'. Some examples of allopoietic systems are: cars, trains, robots etc.

Furthermore, because an allopoietic system is always contingent on the output of other systems for it existence, its teleology and meaning will always reside in the observers world, never in its own - the systems - world.

\section{On the autopoietic status of systems}

To determine whether a system is or is not autopoietic in its organization, Varela et al. [22] have developed six key points or criteria that should be applied to the system; Koskinen [10] restates these criteria as follows:

1. Determine, through interactions, if the unity has identifiable boundaries. If the boundaries can be determined, proceed to 2. If not, the entity is indescribable and we can say nothing.

2. Determine if there are constitutive elements of the unity, that is, components of the unity. If these components can be described, proceed to 3 . If not, the unity is an unanalyzable whole and therefore not an autopoietic system.

3. Determine if the unity is a mechanistic system, that is, if the component properties are capable of satisfying certain relations that determine the unity, the interactions, and transformations of these components. If this is the case, proceed to 4 . If not, the unity is not an autopoietic system.

4. Determine if the components that constitute the boundaries of the unity constitute these boundaries through preferential neighbourhood relations and interactions between themselves, as determined by their properties in the space of their interactions. If this is not the case, you do not have an autopoietic unity because you are determining its boundaries, not the unity itself. If 4 is the case, however, proceed to 5 .
5. Determine if the components of the boundaries of the unity are produced by the interactions of the components of the unity, either by transformation of previously produced components, or by transformations and/ or coupling of non-component elements that enter the unity through its boundaries. If not, you do not have an autopoietic unity; if yes, proceed to 6 .

6. If all the other components of the unity are also produced by the interactions of its components as in 5, and if those which are not produced by the interactions of other components participate as necessary permanent constitutive components in the production of other components, you have an autopoietic unity in the space in which its components exist. If this is not the case and there are components in the unity not produced by components of the unity as in 5 , or if there are components of the unity which do not participate in the production of other components, you do not have an autopoietic unity.

Thus, the successful application of the above six-point taxonomy is sufficient to determine if a system is autopoietically organized (or not).

\section{LUHMANN: AUTOPOEISIS AND SOCIAL SYSTEMS}

In formulating his law of requisite variety William Ross Ashby [2] observed that to survive in a complex environment while maintaining internal stability and structure, a system must be able to generate an appropriate gamut of responses to an ever changing environment. In contrast, General Systems Theory, as formulated by Ludwig von Bertalanffy [4], assumes an open systems model ${ }^{4}$, viewing complex systems in terms of the difference between 'the system and its environment'; contra a closed system model $^{5}$ and mereological distinctions between, say, the physical instantiation of 'whole and parts'.

Influenced by General Systems Theory, the core element of Niklas Luhmann's 'system theoretic' view of social systems is communication: social systems are systems of communication and society $i$ s the most encompassing social system. In Luhmann's view [12] a social system is defined by the boundary between itself and its environment, which is considered an infinitely complex ('chaotic') exterior. Thus, relative to the exterior, the interior of the social system is a space of reduced complexity: communication within a social system operates by selecting only a limited element of all the information available outside the system. In this way Luhmann's concept of communication inherently entails a "reduction of complexity", whereby the criteria according to which information is selected and processed is meaning. Thus social systems are operationally closed because, while they use and rely on resources from their environment, those resources do not become an integral part of the systems' operation.

\footnotetext{
${ }^{4}$ An open system exchanges material, energy, people, capital, information etc. with its environment.

${ }^{5} \mathrm{~A}$ closed system does not allow transfers in or out of the system.
} 
Thus for Luhmann, social systems operate by processing meaning and furthermore, each system has a distinctive identity; a unity, that is constantly reproduced in its communication and depends on what is considered meaningful (and what is not) for that system. If the system fails to maintain this identity, it dies, it ceases to exist and it dissolves back into the wider environmental ether whence it came.

Luhmann conceived this process of continuous reproduction from elements previously filtered from an over-complex environment as autopoiesis ${ }^{6}$.

\section{ART AS AUTOPOIESIS: A BRIEF HISTORICAL REVIEW}

The resonance of art with autpoiesis has been explored by several thinkers, most notably Luhmann who in his theory of social systems [13] famously put forward a 'theory of art' as "a particular system of communication", i.e. ".. the function of art can be traced to problems of meaningful communication" [11]. For Luhmann, the domain of art is to be viewed as an operationally closed and self-referential communicative system, an autopoietic system; radically suggesting that it is ".. from the autopoiesis of art which works of art will be created". This led Rampley, in his review [19], to suggest that the ".. key question Luhmann addresses [in his conception of art and autopoiesis] is how art differentiates itself from other systems".

Although the influence of Luhmann's conception of art [in terms of autopoiesis and communication] continues to be pervasive, it has not gone unchallenged. For example, as early as 2001 Sevanen [20] observed ".. the basic problem in these notions lies in the way in which their description of the relationships existing between different systems is only in very narrow terms. Consequently they partially ignore the present process of de-differentiation which has noticeably changed the status of art in society".

Similarly, albeit in a more recent essay, Schinkel asserts that Luhmann does not have an adequate theory of"The Artworld" [21], but more positively suggests that by "conceiving of 'The Artworld' as an autopoietic social system, Luhmann's highly original work can be brought to bear in the sociology of art".

In addition, explicit links between autopoiesis and artpractise have also been explored; for example, in 2010 Mario Vieira de Carvalho [6] offered a view of twentieth century serialist music through the lens of autopoiesis:

".. in particular, the postulation according to which "the essence of art is the self-programmation of works of art" (ibid: 332) seems to find - for instance, in music - its only realization in some so-called serial works created in the 1950 s by composers from the Darmstadt circle and in some manifestations of aleatoric music."

\footnotetext{
${ }^{6} \mathrm{NB}$. Both Varela and Maturana have forcefully argued against this appropriation of the term autopoiesis; in Maturana and Varela's conception, people cannot be proper elements of a social system's renewal because (a) in describing social systems as operationally closed networks of communications, Luhmann ignores the fact that communications presuppose human communicators [17] and (b) people are not (re)produced as an integral and core part of a social system's renewal processes [18].
}

"The homologies between Luhmann's theory of art and the theory of serial music from the early fifties seem in this way to be evident. They have in common a concept of self-reference and of autopoiesis that radically excludes a critical interaction both of science and art (as socio-communicative systems) with real life."

However as the notion of autopoiesis and art has become more widespread in the arts, social sciences and humanities, Maturana and Varela's original, tightly theoretic, definition (as outlined above) has become more and more blurred, such that in her recent art project, "AUTOPOIESIS" (2014), the academic and artist Btihaj Ajana (the project's curator) merely offers autopoiesis as being (i) synonymous with, "the act of self-creation and self-production" and (ii) in the context of the AUTOPOIESIS exhibition, merely ".. a metaphor for what this experimental cultural project is all about"; indeed there is now an established tradition of using autopoiesis simply as a metaphorical springboard for inspiration in art, with numerous exhibitions and artworks taking their cue from the term $^{7}$.

\section{'CREATIVITY’ AS AN AUTOPOIETIC PROCESS}

\section{Historical}

A traditional, representation-heavy, view of the artist as an open-system, fundamentally posits his activities as contingent on external influences; the artist responds creatively to demands from a pre-given, objective environment by building and creatively processing appropriate internal representations. In this view, through his practise, the artist builds representations of a pre-given reality - universal, objective, and transferable - and it is his role, as artist, to transform these representations in novel, interesting and creative ways.

The contrary, autopoietic perspective reflects that creativity is autonomous and operationally closed ${ }^{8}$. In addition, autopoietic creative systems stand 'structurally coupled' with their medium; fundamentally embedded in a dynamic of changes, exercised via appropriate sense-action coupling. This continuous dynamic can be considered a rudimentary form of creative knowledge.

Emerging from a General System Theory perspective, the exploration of autopoiesis in the context of 'creativity studies' was first outlined by Gornev in 1997 [7] who first set out to construct a theory of human creativity on the foundation of autopoietic systems theory (AST), whereby:

"creativity is seen as an activity recurrently reproduced by couplings of specific states of moderate emotional arousal with transitional environments, i.e. soft social structures in which the world is permitted to be both subjective and objective; the archetype of these creative

\footnotetext{
${ }^{7} \mathrm{Eg}$. Alongside Btihaj Ajana there have also been recent exhibitions from artists as diverse as Ken Rinaldo; Sean Clark, Robert Genn etc etc.

${ }^{8}$ It is operationally close in the sense that there are sufficient processes within it to maintain the unity of creation and that, while they use (and rely upon) resources from their environment, those resources do not themselves become an integral core element of the creative systems' operation.
} 
couplings can be found in the earliest perfect environment formed by the symbiotic infant/mother relationship".

In contrast in 2010 Takashi Iba [8] defined "Creative Systems Theory" in order to view creative processes ${ }^{9}$ in an alternative way, ".. focusing the process itself without the reference to psychic or social aspects". In his work Iba postulated creative processes to be "autopoietic systems whose elements are 'discoveries' emerged by a synthesis of three selections: idea, association, and consequence".

However, by merely defining that "creativity is an autopoietic system whose element is discovery", Iba's work, like Gornev's first tentative explorations thirteen years earlier, remains floating very much at a conceptual level; it offers little insight into how 'creative process' at the personal, 'psychic', artistic level could ever actually be cached out; indeed, as he stated in the paper (ibid), this was never his project.

\section{Our view}

Conversely, and in an analogous manner to Luhmann's conception of information processing, we view creativity as entailing a reduction in complexity of meaning in the environment; with the system operationally closed because, while its creativity uses and relies upon resources from its environment, these resources do not become part of the underlying systems' operation.

Viewed under this conception, a creative system (a) processes meaning and (b) maintains a distinctive identity; a unity that is repeatedly reproduced in its operation, contingent upon what is considered meaningful (or not) for the system. If the environmental conditions are such that, over time, the creative system can no longer maintain this identity, then its investigations will simply dissolve away to void.

In this way creativity is a constructive process; it inherently reflects an individually constructed artistic reality. Furthermore, because autopoietic creativity emerges from the observation of distinctions and not of things, its operation is fundamentally contingent on its own history, and in this way is ever-sensitive to its own historical context.

In summary, and in contrast to the classical view of creative processes building (reflecting on and transforming) representations of a pre-given, out-there, world, an autopoietic view of creativity is based on the simultaneous knowledge processes of sensing and memory. In this context memory ${ }^{10}$ entails that:

- the unity has access to its existing knowledge;

- previous, accumulated, knowledge modulates the the unity's ongoing structures and operations;

\footnotetext{
${ }^{9}$ Iba defines that a creative process consists of "a sequence of discoveries, which include problem finding, problem solving, observation, hypothesis formation, method selection, practice, and interpretation", (ibid).

${ }^{10} \mathrm{~A}$ self-referential process which facilitates access to, and learning from, previous experiences and knowledge [10].
}

- the unity's cognitive structures and operation affect its acquisition of new data from the environment and its creation of new internal knowledge structures.

Furthermore, we observe that by conceptualising creative processes within an autopoietic framework, we must conclude that creativity is never a directly transferable skill or knowledge ${ }^{11}$.

\section{THE AUTOPOIETIC ARTIST}

The continual creative swarmic processes of our autopoietic artists' attention and reconstitution (sketching) mechanisms are detailed sections below and are illustrated in accompanying video, which displays her behaviour as she iteratively decodes a line-sketch of an abstract painting by Willem De Kooning ${ }^{12}$.

The 'autopoietic' artist is composed of two functionally distinct types of agent: (i) a swarm of attending agents ${ }^{13}$, akin to ants (and governed by the principles of Stochastic Diffusion Search (SDS) [5] ) and (ii) a swarm of drawing agents akin to birds (and governed by the principles of a Particle Swarm Optimiser (PSO) [9]). The job of the attending agents is to select areas of meaning ${ }^{14}$ for the drawing agents to 're-interpret'.

Our 'autopoietic' artist is thus continually engaged in a process of sensing her environment and reconstituting it (by iteratively first choosing a line in the scene and re-rendering it). The bounds of the autopoietic artist are defined by the shifting movements of the swarms that comprise her; the elements of the autopoietic artist are the agents of the swarms; the behaviour of each swarm is fully defined by the behaviour of its agents (SDS and PSO); the bounds of the swarms are defined by the hypotheses (positions) of all the SDS agents, whose behaviour changes and in turn modifies the bounds; the components of the boundaries are produced by the interactions of the components of the unity, by transformation of previously produced hypotheses; and because the iterative reinitialisation of the SDS agent-hypotheses are produced by the interactions of the SDS swarm (and all other PSO agents participate as necessary permanent constitutive components

\footnotetext{
${ }^{11} \mathrm{Cf}$. Koskinen on 'autopoietic knowledge systems in project-based companies' [ibid]

${ }^{12} \mathrm{Cf}$. https://youtu.be/EtEAAilhbFw. In our example the artistic environment is initially an outline sketch of Kooning's abstract canvas, displayed initially in the right-hand panel of the video; with the creative output, displayed on the left.

${ }^{13}$ In [3] Francisco de Paula Barretto and Suzete Venturelli outline a evolutionary multi-agent system inspired by autopoiesis, that has been deployed in a computer game ('Zer0') to compose emergent music in real time. Although the authors note the influence of autopoiesis in their conceptualisation, the Barretto and Venturelli paper fails to expand any manner in which the Zer0 agents qualify as autpoietic systems; indeed their use of explicit goals and internal representations argue against this conceptualisaiotn being fully merited. For these reasons we are unable to consider [3] further in this exposition.

${ }^{14}$ For example, in our system we have defined such an area of interest (or 'meaning distinction') to be a line situated in a complex region of the image; an area that is rich/dense in comparison with other lines. Thus, by suitably redefining the distinction deployed by the population of Stochastic Diffusion agents (as described in Section V), we can modify what constitutes 'meaning' for the autopoietic artist as she interacts with her creative context/environment.
} 
in the production of other components), Varela et al's criteria [22] for an autopoietic entity are appropriately instantiated in the organisation of our 'autopoietic' artist in the creative space in which her creative unity exists.

Thus, following Luhmann's conception of information processing, we view the working autopoietic artist as entailing a reduction in complexity, ravenously consuming 'meaningdistinctions' within her environment; in this way the autopoietic artist iteratively decodes her environment by continuously first selecting, then processing, areas of meaning

Over time, with her artistic 'interest' drawn to areas of rich complexity, the autopoietic artist, so construed, iteratively erases meaningful-distinctions (lines) in her current artistic context, so gradually simplifying the structure of the work. By iteratively focussing on meaning-distinctions as-areas-ofrich-complexity, as the decoding process unfolds it sometimes leads to a less complex (line) structure and ultimately may result in an empty canvas; therein reifying the artwork's 'death' and the tabula rasa.

Alternatively, by refocussing the autopoietic artist's reflections on 'meaning' (as explored by the Stochastic Diffusion swarm) onto different constitutive elements, and modifying her reconstitution (of the resulting artistic structure), different behaviours of autopoietic creativity can be induced. E.g. By insisting that the reconstitutive processes must generate as many elements of 'meaning-distinction' as they consume, the induced autopoietic processes becomes less likely to fade away and more open-ended in their creative endeavour.

\section{CONCLUSION: THE AUTOPOIETIC ARTIST AS A 'WEAKLY' CREATIVE SYSTEM}

In summary, in the context of Al-Rifaie and Bishop's 'weak' and 'strong' taxonomy of [computational] creativity [14], although we have presented autopoiesis as offering a new conception of 'strong' artistic creativity, with her 'operational processes' externally instantiated in the execution of a computer program ${ }^{15}$ and her idea of 'meaning' (e.g. as areas of high image density/complexity) externally engineered ${ }^{16}$, sensu-stricto the particular computational autopoieticic artist described herein, fundamentally remains an allopoietic system; we offer her merely as a simple epistemic lens though which to better view, understand and frame the underlying processes of creativity, and not as a computational instantiation of strong creativity. As argued elsewhere [14], any such ontological claim must entail much more serious engagement with the physical embodiment of the underlying autopoietic system.

\footnotetext{
${ }^{15}$ There is an old debate in the field of computational autopoiesis that effectively rests of the following question: is a computational simulation of an autopoietic entity a genuine autopoietic unity? Those who argue not assert that because the components of, say, the computational autopoietic artist described herein, are fundamentally instantiated via a computer simulation, (whose organisation - power, hardware and software etc - they do not participate in regenerating and maintaining)

${ }^{16}$ Contra Maturana and Varela's conception of autopoiesis as a system description to define and explain the nature of living systems as fully autonomous entities, each with a unique teleological behaviour.
}

\section{REFERENCES}

1. al-Rifaie, M.M., Aber, A. and Bishop, J.M., (2012), Cooperation of Nature and Physiologically Inspired Mechanisms in Visualisation, in Ursyn, A. (Ed), Biologically-Inspired Computing for the Arts: Scientific Data through Graphics, IGI Global, United States, ISBN13: 9781466609426.

2. Ashby, W. R. (1956). An Introduction to Cybernetics. London: Chapman and Hall.

3. Barretto, F. P. and Venturelli, S. (2015). Zer0: an emergent and autopoietic multi-agent system for novelty creation in game art through gesture interaction, 6th International Conference on Applied Human Factors and Ergonomics (AHFE 2015) and the Affiliated Conferences, AHFE 2015, published in Procedia Manufacturing: 3, pp. 850-857.

4. Bertalanffy, L. von, (1968). General System theory: Foundations, Development, Applications, New York: George Braziller, revised edition 1976: ISBN 0-8076-0453-4

5. Bishop, J.M., (1989), Stochastic Searching Networks, Proc. 1st IEE Conf. on Artificial Neural Networks, pp. 329-331, London, UK.

6. Carvalho, M.V. (2001). Art as Autopoiesis? A critical approach, beginning with the European musical avant-garde in the early 1950s, Journal of Sociocybernetics 2(1), pp. 33-41.

7. Gornev, G.P. (1997). The creativity question in the perspective of autopoietic systems theory, Kybernetes: 26(6/7), pp.738-750.

8. Iba, T. (2010). An Autopoietic Systems Theory for Creativity. Proc. COINs2009: Collaborative Innovation Networks Conference published in, Procedia Social and Behavioral Sciences: 2, pp. 66106625.

9. Kennedy, J. \& Eberhart, R.C., (1995), Particle swarm optimization, Proc. IEEE International Conference on Neural Networks: IV, pp.1942-1948, Piscataway, NJ.

10. Koskinen, K.U., (2010). Autopoietic Knowledge Systems in Project-Based Companies, Palgrave Macmillan, UK.

11. Luhmann, N. (1995). Social Systems. Stanford: Stanford University Press.

12. Luhmann, N. (1995). Gesellschaftsstruktur und Semantik 4: Studien zur Wissenssoziologie der modernen Gesellschaft (Structure of Society and Semantic 4: Studies on Knowledge-Sociology of Modern Society). Frankfurt am Main: Suhrkamp.

13. Luhmann, N. (1996). Die Kunst der Gesellschaft. Frankfurt a. M.: Suhrkamp.

14. Al-Rifaie, M.M. \& Bishop, J.M., (2015), Weak and Strong Computational Creativity, in Besold, TR, Schorlemmer M \& Smaill A, (Eds) (2015), Computational Creativity Research: Towards Creative Machines, 37-51, Springer. 
15. Maturana, H. and F. Varela, (1973). De Mquinas y Seres Vivos: Una teora de la organizacon biolgica. Santiago de Chile: Editorial Universitaria. (Reprinted in English in Maturana, H. and F. Varela, (1980)).

16. Maturana, H. and F. Varela, (1980). Autopoiesis and Cognition: The Realization of the Living. Boston: D. Reidel.

17. Maturana, H., \& Poerkson, B. (2004). From Being to Doing: The Origins of the Biology of Cognition. Carl Auer International. pp. 105108. ISBN 3896704486.

18. Maula, M. (2006). Organizations as Learning Systems: Living Composition" as an Enabling Infrastructure (Advanced Series in Management), Elsevier.

19. (2009), Rampley, M. Art as a Social System: The Sociological Aesthetics of Niklas Luhmann, Telos: 148, pp. 111-140.

20. Sevanen, E. (2001). Art as an Autopoietic Sub-System of Modern Society: A Critical Analysis of the Concepts of Art and Autopoietic Systems in Luhmann's Late Production, Theory, Culture \& Society: 18(1), pp. 75-103.

21. Schinkel, W. (2010). The Autopoiesis of the Artworld after the End of Art. Cultural Sociology: 4(2), pp. 267-290.

22. Varela, F. J., Maturana, H. R., and Uribe, R. (1974). Autopoiesis: The Organization of Living Systems, Its Characterization and a Model. Biosystems, 5(4), pp. 187-96.

23. Whitehead, A.N., (1929), Process and Reality, New York: Macmillan. 